\title{
Women's Satisfaction Toward IVF ( In Vitro Fertilization) Care in Public Versus Private Center.
}

\author{
Mona Rabeea Ahmed ${ }^{1}$, Manal Farouk Mostafa ${ }^{2}$, Ghadah Abdelrahaman Mahmoud ${ }^{3}$ \& Tarek A Farghaly $^{4}$ \\ 1. Assistant Lecturer, Faculty of Nursing, Assiut University, Egypt. \\ 2. Professor of Obstetrics \& Gynecological Nursing, Faculty of Nursing, Assiut University, Egypt. \\ 3. Professor of Obstetrics \& Gynecological Nursing, Faculty of Nursing, Assiut University, Egypt. \\ 4. Lecturer of Obstetrics \& Gynecology, Faculty of Medicine, Assiut University, Egypt.
}

\begin{abstract}
Background: The satisfaction of patients is increasingly recognized as one of the fundamental dimensions of quality of care, especially with infertility treatment. Aim of the study was to measure women's satisfaction toward IVF care in public versus private center. Subjects \& methods: Descriptive comparative design , conducted at two centers (Banoon private center for IVF and Assisted Reproductive Unit at Women health hospital), Systematic random sample was used in this study included 300 women (150 from each center). The used tool was structured interviewing questionnaire included (Personal data, Menstrual history, Infertility history,etc) \& Scale of women satisfaction about IVF care(Gonen,2016). Results: There is statistical significant difference between satisfaction in public and private centers as regards to information provided, willingness of staff to listen carefully and help women $\&$ Report the women about regular progress of the condition with p.v (.000, .005, .003) respectively. Conclusion: There was statistical significant difference between satisfaction in public and private center as regards information provided, willingness of staff to listen carefully and help women. Recommendations: Medical staff should spend more time in consulting and providing more explanation to improve women's satisfaction.
\end{abstract}

\section{Keywords: Women's Satisfaction \& In Vitro Fertilization.}

\section{Introduction}

Infertility is a disease characterized by the inability to create a clinical pregnancy after 12 months of frequent, unprotected sexual intercourse or by an deficiency in the ability of a person to reproduce either as an person or with his or her partner. (ZegersHochschild et al., 2017)

The first IVF baby was born in England in 1978 after more than twenty years of research. However; more than 250,000 children have been conceived as a consequence of using IVF method from this point forward. (Obioha et al., 2014)

In Vitro Fertilization (IVF) is a human-assisted technology of reproduction that helps a woman who is infertile to get pregnant. It involves four fundamental measures: 1) stimulating the ovaries to develop numerous ovarian follicles;

2) Aspiring mature oocytes from the ovaries of the woman with ultrasound guidance under anesthesia; (3) oocytes and sperm are put in the laboratory to allow fertilization, and (4) embryos are transmitted to the woman's uterus for the establishment of pregnancy (Bayer, et al., 2017)

IVF was created for women with tubal infertility, but its indications soon began to grow. In the 1990s intracytoplasmic sperm injection was developed to treat couples in which the man has bad semen quality that prohibits sperm from coming near to an egg like tubal infertility. (Kamphuis et al., 2014)
Clients ' satisfaction with medical care is increasingly acknowledged as one of the fundamental aspects of quality care, particularly in the treatment of infertility. (Gonen, 2016)

Patient satisfaction is a significant measure that is commonly used to assess health care quality. Patient satisfaction impacts clinical outcome, retention of patients and claims of medical malpractice. It affects delivery of quality health care in a timely, efficient and patient-centered manner. Patient satisfaction is therefore a proxy but a very efficient indicator for measuring physicians and hospitals ' achievement. (Prakash, 2010)

\section{Significant of the study}

Infertility is estimated to be as high as 186 million individuals globally. Recent global demographic surveys reveal that infertility continues to be a reproductive problem, in spite of the massive global increase of ART services over the past decade. It is estimated that infertility affects 8 to 12 percent of reproductive-age couples around the world. However, the infertility rates are much higher in some regions of the world, reaching 30\% in some regions. (Ghraib \& Khait, 2017). In Egypt, infertility incidence has been estimated to be $10.4 \%$ of married couples (Eltoukhi, et al., 2017) Infertility is a traumatic event, and assisted reproductive techniques are now a revolution for treatment. In vitro fertilization is a commonly 
performed technique. Many factors affect the IVF procedure success and outcomes. (Eltoukhi et al., 2017) Increasing patient satisfaction with IVF services, treatments and facilities has a positive effect on patients ' psychological and mental state and, in turn, has an impact on the outcome of treatments and dropout rates of treatment. (Gonen, 2016) So, this study will shed more light on women's satisfaction toward IVF care in two centers.

\section{Aim of the study}

The aim of the study was to measure women's satisfaction toward IVF care in public versus private center.

\section{Research questions}

What is the level of women's satisfaction toward IVF care?

Is there difference between women's satisfaction in public IVF center and women's satisfaction in private IVF center?

\section{Subjects \& Methods}

Research design: It was descriptive comparative research design.

Setting of the study: The study was conducted at two centers (Banoon private center for IVF and Assisted Reproductive Unit at Women health hospital, Assiut University)

\section{Sample}

Systematic random sample was used in this study. Random assignment was done by computer generated tables .The Sample was calculated by using (Epi-info statistical package, version 7.2which designed by CDC )(center for disease control and prevention) with $80 \%$ power, a value of 2.5 is chosen at the acceptable limit of precision (D) at $95 \%$ confidence level (C1) with expected prevalence10\%, worst acceptable $25 \%$.accordingly, sample size was estimated to be 300 (150 for each group) $+10 \%$ of individual to guard against non-respondence rate.

\section{Inclusion criteria}

1. Women undergoing IVF treatment

2. Women who agree to participate in the study

Exclusion criteria

1. Women who had any medical problems

2. Women who were older than 37 yrs.

3. Women with signs of reduced ovarian reserve as elevated FSH levels.

Tools

Tools of the study

Tool no. (1) Structured interviewing questionnaire include

Part I: Personal data that was included: Name, age, residence, educational level, occupation, and duration of marriage.

\section{Part II: clinical data}

1- Medical history was included: the history of diabetes, hypertension, renal disease, cardiac disease, hepatic disease, and any other diagnosed medical disease.

2- Menstrual history was included: Age of menarche, Duration, Interval, and rhythm

3- Infertility history was included: years of infertility, type of infertility, cause of it, previous trial for ART, previous failed IVF.

4- Past obstetric history was included: number of gravidity, number of parity, number of abortion, No of living children, time since last delivery or abortion.

Tool (2) Scale of patient satisfaction about IVF (Gonen, 2016)

-Satisfaction about information provided (5 items).

-Satisfaction about staff communications \& counseling and support (5 items).

-Satisfaction about environmental conditions\& waiting time ( 3 items).

Evaluation of treatment questions about satisfaction were presented on 7-point Likert scale

1 represents 'Completely dissatisfied'; 2 represents 'Mostly dissatisfied'; 3 represents 'Somewhat dissatisfied'; 4 represents 'neither satisfied or dissatisfied', 5 represents 'Somewhat satisfied'; 6 represents 'Mostly satisfied' and 7 represents 'Completely satisfied'

Scoring system

$-60 \%$ or more represents satisfied, $40 \%$ or less represents dissatisfied

$-1,2,3$ represent dissatisfied; 4,5,6,7 represent satisfied (Gonen, 2016)

\section{Methods}

\section{Methods of data collection}

- A review of national and international related literature of the current study using text books, articles and scientific journals was done.Then the tool was prepared based on this literature and it was reviewed for validation by supervisors.

- Before conducting the study an official permission was obtained from the manager of Banoon center and Assisted Reproductive Unit of Women's Health Hospital after explaining the purpose of the study.

- Apilot study was carried out on $10 \%$ of cases (30 case) to test the clarity of the questions and to detect any further problems or difficulties that help in making the necessary modification. There wasn't any modification on the tool and the pilot sample was included in the total sample.

- The study was carried out during the period from Feburary (2018) to November (2018). 
- The study was conducted at Banoon center and Assisted Reproductive Unit of Women health hospital and was included simple random sample of 300 Women undergoing IVF treatment (150 from each center).

- The participants were divided into two groups Group A undergoing IVF treatment at public IVF center (150 women).

Group B undergoing IVF treatment at Banoon Private IVF center (150 women).

\section{Assessment phase}

The researcher interviewed the women face to face; each interview took about 15-30 minutes at the stage of induction of ovulation, and at the beginning of each interview, the researcher greeted, introduced herself to the woman after that the researcher explained the nature and aim of study, and then an oral consent to participate in the study was obtained from each woman. Then, the researcher assessed the following data

1-Personal data, menstrual history, infertility history\& past obstetrical history if present.

2- Satisfaction scale.

\section{Validity and Reliability}

Content validity was ascertained by a group of (3) experts from obstetrical \& Gynecological nursing at faculty of nursing. Their opinions were elicited regarding the tool format layout, and scoring system .The content of the tool tested regarding the knowledge accuracy, relevant and competency and for the reliability, the tools were confirmed for consistency by cronbach's alpha test. Coeffeciency (alpha $=.871 ; .890 \& 0.21)$ respectively

\section{Ethical considerations}

1. Research proposal was approved from Ethical Committee in the Faculty of Nursing

2. There was no risk for study subject during application of the research.

3. The study was followed common ethical principles in clinical research.

4. Written consent was obtained from each patient or guidance that was willing to participate in the study.

5. Confidentiality and anonymity was assured.

6. Patient's privacy was considered during collection of data.

Statistical analysis

Data entry and statistical was done using the statistical package for social science program (SPSS. version 22).qualitative variables were presented as number and percentage. Quantitative variables were presented as mean + SD. Comparsion between qualitative variables was done by using chi-square. Comparsion between quantitative variables was done by using student t-test.

\section{Results}

Table (1): Distribution of studied women according to their Socio-demographic characteristics among both groups.

\begin{tabular}{|c|c|c|c|c|c|}
\hline \multirow{2}{*}{ Sociodemographic characteristics } & \multicolumn{2}{|c|}{ public IVF center $N=150$} & \multicolumn{2}{|c|}{ private $I V F$ center $N=150$} & \multirow{2}{*}{ P-Valuc } \\
\hline & $\mathbf{N}$ & $\%$ & $\mathbf{N}$ & $\%$ & \\
\hline $\begin{array}{l}\text { Age (years) } \\
<25 \text { yrs }\end{array}$ & 19 & $12.7 \%$ & 27 & $18 \%$ & \multirow{3}{*}{.440} \\
\hline $25-<30$ yrs & 52 & $34.7 \%$ & 49 & $32.7 \%$ & \\
\hline $30-37 y r s$ & 79 & $52.7 \%$ & 74 & $49.3 \%$ & \\
\hline $\begin{array}{l}\text { Residence } \\
\text { Urban }\end{array}$ & 32 & $21.3 \%$ & 55 & $36.7 \%$ & \multirow[t]{2}{*}{ *.009 } \\
\hline Rural & 118 & $78.7 \%$ & 95 & $63.3 \%$ & \\
\hline \multicolumn{5}{|l|}{ Educational level } & \multirow{5}{*}{${ }^{*} .002$} \\
\hline Illiterate \&read and write & 31 & $20.7 \%$ & 16 & $10.7 \%$ & \\
\hline Basic education & 22 & $14.7 \%$ & 9 & $6 \%$ & \\
\hline Secondary & 72 & $49 \%$ & 99 & $66 \%$ & \\
\hline High education & 25 & $16.7 \%$ & 26 & $17.3 \%$ & \\
\hline $\begin{array}{l}\text { Occupation } \\
\text { Employee }\end{array}$ & 24 & $16 \%$ & 20 & $13.3 \%$ & \multirow[t]{2}{*}{.514} \\
\hline House wife & 126 & $84 \%$ & 130 & $86.7 \%$ & \\
\hline $\begin{array}{l}\text { Years of marriage } \\
\text { Less than } 1 \mathrm{yr}\end{array}$ & 1 & $.7 \%$ & 1 & $.7 \%$ & \multirow{4}{*}{.542} \\
\hline $1-5 y r s$ & 48 & $32 \%$ & 59 & $39.3 \%$ & \\
\hline $5-10 y r s$ & 65 & $43.3 \%$ & 54 & $36 \%$ & \\
\hline More than $10 \mathrm{yrs}$ & 36 & $24 \%$ & 36 & $24 \%$ & \\
\hline
\end{tabular}


Table (2): Distribution of women's satisfaction about information provided in public IVF center versus in private IVF center.

\begin{tabular}{|c|c|c|c|c|c|}
\hline & \multicolumn{2}{|c|}{ Public IVF center } & \multicolumn{2}{|c|}{ private IVF center } & \multirow{2}{*}{ p-value } \\
\hline & $\mathbf{N}(150)$ & $\%$ & $\mathbf{N}(150)$ & $\%$ & \\
\hline \multicolumn{5}{|c|}{ 1-Information on the chances of success } & \multirow{8}{*}{$.000 *$} \\
\hline completely dissatisfied & $\ldots \ldots$ & ..... & $\ldots \ldots$ & ..... & \\
\hline Mostly dissatisfied & ..... & $\ldots .$. & 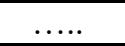 & ..... & \\
\hline Somewhat dissatisfied & 5 & $3.3 \%$ & 8 & $5.3 \%$ & \\
\hline Neither satisfied nor dissatisfied & 10 & $6.7 \%$ & 3 & $2.0 \%$ & \\
\hline Somewhat satisfied & 38 & $25.3 \%$ & 7 & $4.7 \%$ & \\
\hline Mostly satisfied & 16 & $10.7 \%$ & 20 & $13.3 \%$ & \\
\hline Completely satisfied & 81 & $54 \%$ & 112 & $74.7 \%$ & \\
\hline \multicolumn{5}{|c|}{$\begin{array}{l}\text { 2-Information on prognosis, different treatment options, clinical aspects, and possible side } \\
\text { effects of treatment }\end{array}$} & \multirow{8}{*}{$* 000$} \\
\hline Completely dissatisfied & 4 & $2.7 \%$ & 0 & $.0 \%$ & \\
\hline Mostly dissatisfied & 1 & $.7 \%$ & 0 & $.0 \%$ & \\
\hline Somewhat dissatisfied & 33 & $22.0 \%$ & 16 & $10.7 \%$ & \\
\hline Neither satisfied nor dissatisfied & 13 & $8.7 \%$ & 4 & $2.7 \%$ & \\
\hline Somewhat satisfied & 19 & $12.7 \%$ & 14 & $9.3 \%$ & \\
\hline Mostly satisfied & 7 & $4.7 \%$ & 38 & $25.3 \%$ & \\
\hline Completely satisfied & 73 & $48.7 \%$ & 78 & $52.0 \%$ & \\
\hline \multicolumn{5}{|c|}{ 3-Information about potential health problems of (defects, prematurity) } & \multirow{8}{*}{$* .004$} \\
\hline Completely dissatisfied & $\ldots$ & $\ldots$ & $\ldots$ & $\ldots$ & \\
\hline Mostly dissatisfied & 6 & $4 \%$ & 0 & $0 \%$ & \\
\hline Somewhat dissatisfied & 32 & $21.3 \%$ & 40 & $26.7 \%$ & \\
\hline Neither satisfied or dissatisfied & 18 & $12.0 \%$ & 7 & $4.7 \%$ & \\
\hline Somewhat satisfied & 17 & $11.3 \%$ & 11 & $7.3 \%$ & \\
\hline Mostly satisfied & 6 & 4 & 15 & $10 \%$ & \\
\hline Completely satisfied & 71 & $47.3 \%$ & 77 & $51.3 \%$ & \\
\hline \multicolumn{5}{|c|}{$\begin{array}{l}\text { 4-Information about medical issues during pregnancy (multiple pregnancies, ectopic } \\
\text { pregnancies, etc.) }\end{array}$} & \multirow{8}{*}{$* .026$} \\
\hline Completely dissatisfied & 4 & $2.7 \%$ & $\ldots \ldots$ & $\cdots \cdots \cdots$ & \\
\hline Mostly dissatisfied & 1 & $.7 \%$ & $\ldots \ldots$ & & \\
\hline Somewhat dissatisfied & 36 & $24 \%$ & 40 & $26.7 \%$ & \\
\hline Neither satisfied nor dissatisfied & 14 & $9.3 \%$ & 5 & $3.3 \%$ & \\
\hline Somewhat satisfied & 18 & $12 \%$ & 13 & $8.7 \%$ & \\
\hline Mostly satisfied & 6 & $4 \%$ & 15 & $10 \%$ & \\
\hline Completely satisfied & 71 & $47.3 \%$ & 77 & $51.3 \%$ & \\
\hline \multicolumn{5}{|l|}{ 5-Information on treatment costs } & \multirow{8}{*}{$* .000$} \\
\hline Completely dissatisfied & $\ldots$ & $\ldots$ & $\ldots$ & $\ldots$ & \\
\hline Mostly dissatisfied & $\ldots$ & $\ldots$ & $\ldots$ & $\ldots$ & \\
\hline Somewhat dissatisfied & 4 & $2.7 \%$ & $\ldots$ & $\ldots$ & \\
\hline Neither satisfied nor dissatisfied & 9 & $6.0 \%$ & $\ldots$ & $\ldots$ & \\
\hline Somewhat satisfied & 32 & $21.3 \%$ & 5 & $3.3 \%$ & \\
\hline Mostly satisfied & 14 & $9.3 \%$ & 19 & $12.7 \%$ & \\
\hline Completely satisfied & 91 & $60.7 \%$ & 126 & $84 \%$ & \\
\hline
\end{tabular}

(*) statistically significant difference 
Table (3): Distribution of women's satisfaction about staff communications \& counseling and support in public IVF center versus in private IVF center.

\begin{tabular}{|c|c|c|c|c|c|}
\hline & \multicolumn{2}{|c|}{ Public IVF center } & \multicolumn{2}{|c|}{ Private IVF center } & \multirow{2}{*}{ p-value } \\
\hline & $\mathbf{N}(150)$ & $\%$ & $\mathbf{N}(150)$ & $\%$ & \\
\hline \multicolumn{5}{|c|}{ 1-Attitude of fertility clinic staff and their relationship with patients } & \multirow[t]{8}{*}{.110} \\
\hline Completely dissatisfied & $\ldots .$. & $\ldots .$. & $\ldots .$. & $\ldots .$. & \\
\hline Mostly dissatisfied & ..... & ..... & ..... & ..... & \\
\hline Somewhat dissatisfied & $\ldots .$. & $\ldots .$. & $\ldots .$. & $\ldots .$. & \\
\hline Neither satisfied nor dissatisfied & ..... & $\ldots .$. & $\ldots .$. & $\ldots .$. & \\
\hline Somewhat satisfied & 2 & $1.3 \%$ & $\ldots . .$. & $\ldots \ldots$ & \\
\hline Mostly satisfied & 10 & $6.7 \%$ & 18 & $12.0 \%$ & \\
\hline Completely satisfied & 138 & $92.0 \%$ & 132 & $88.0 \%$ & \\
\hline \multicolumn{5}{|c|}{ 2-No change in the fertility clinic staff from start of treatment to end } & \multirow{8}{*}{.112} \\
\hline Completely dissatisfied & $\ldots .$. & $\ldots .$. & $\ldots .$. & $\ldots .$. & \\
\hline Mostly dissatisfied & $\ldots$. & $\ldots$. & $\ldots$. & $\ldots$. & \\
\hline Somewhat dissatisfied & $\ldots .$. & $\ldots . .$. & $\ldots .$. & $\ldots .$. & \\
\hline Neither satisfied nor dissatisfied & $\ldots .$. & $\ldots .$. & $\ldots$ & $\ldots$ & \\
\hline Somewhat satisfied & $\ldots .$. & $\ldots .$. & $\ldots .$. & $\ldots .$. & \\
\hline Mostly satisfied & 10 & $6.7 \%$ & 18 & $12.0 \%$ & \\
\hline Completely satisfied & 140 & $93.3 \%$ & 132 & $88.0 \%$ & \\
\hline \multicolumn{5}{|c|}{ 3- Staff are willing to listen carefully and help patients } & \multirow{8}{*}{$* .005$} \\
\hline Completely dissatisfied & ..... & $\ldots .$. & $\ldots .$. & $\ldots .$. & \\
\hline Mostly dissatisfied & $\ldots \ldots$ & $\ldots \ldots$ & $\ldots \ldots$ & ..... & \\
\hline Somewhat dissatisfied & $\ldots .$. & $\ldots \ldots$ & $\ldots \ldots$ & $\ldots \ldots$ & \\
\hline Neither satisfied nor dissatisfied & $\ldots .$. & $\ldots .$. & $\ldots$ & $\ldots \ldots$ & \\
\hline Somewhat satisfied & $\ldots \ldots$ & $\ldots \ldots$ & $\ldots \ldots$ & $\ldots \ldots$ & \\
\hline Mostly satisfied & 37 & $24.7 \%$ & 18 & $12.0 \%$ & \\
\hline Completely satisfied & 113 & $75.3 \%$ & 132 & $88.0 \%$ & \\
\hline \multicolumn{5}{|c|}{$\begin{array}{l}\text { 4- Regular progress update on condition is } \\
\text { in place }\end{array}$} & \multirow{8}{*}{$* .003$} \\
\hline Completely dissatisfied & $\ldots .$. & 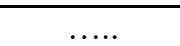 & $\ldots \ldots$ & $\ldots .$. & \\
\hline Mostly dissatisfied & $\ldots \ldots$ & ..... & ..... & ..... & \\
\hline Somewhat dissatisfied & $\ldots \ldots$ & $\ldots .$. & $\ldots .$. & $\ldots .$. & \\
\hline Neither satisfied nor dissatisfied & $\ldots \ldots$ & ..... & $\ldots$ & $\ldots \ldots$ & \\
\hline Somewhat satisfied & 2 & $1.3 \%$ & $\ldots \ldots$ & f....... & \\
\hline Mostly satisfied & 39 & $26.0 \%$ & 18 & $12.0 \%$ & \\
\hline Completely satisfied & 109 & $72.7 \%$ & 132 & $88.0 \%$ & \\
\hline \multicolumn{5}{|l|}{ 5- Medication is provided on time } & \multirow{8}{*}{.171} \\
\hline Completely dissatisfied & $\ldots \ldots$ & $\ldots \ldots$ & $\ldots \ldots$ & $\ldots \ldots$ & \\
\hline Mostly dissatisfied & $\ldots \ldots$ & $\ldots .$. & $\ldots .$. & $\ldots \ldots$ & \\
\hline Somewhat dissatisfied & $\ldots$. & 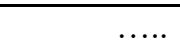 & $\ldots .$. & 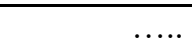 & \\
\hline Neither satisfied nor dissatisfied & $\ldots \ldots$ & $\ldots .$. & $\ldots .$. & $\ldots .$. & \\
\hline Somewhat satisfied & $\ldots$ & $\ldots .$. & $\ldots .$. & 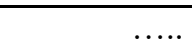 & \\
\hline Mostly satisfied & 11 & $7.3 \%$ & 18 & $12.0 \%$ & \\
\hline Completely satisfied & 139 & $92.7 \%$ & 132 & $88.0 \%$ & \\
\hline
\end{tabular}


Table (4): Distribution of women's satisfaction about physical conditions\&waiting time in public IVF center versus in private IVF center.

\begin{tabular}{|c|c|c|c|c|c|}
\hline & \multicolumn{2}{|c|}{ public IVF center } & \multicolumn{2}{|c|}{ private IVF center } & \multirow{2}{*}{ p-value } \\
\hline & $\mathbf{N}(\mathbf{1 5 0})$ & $\%$ & $\mathbf{N}(150)$ & $\%$ & \\
\hline \multicolumn{5}{|c|}{ 1-Environmental conditions in the operating room } & \multirow{8}{*}{.281} \\
\hline Completely dissatisfied & $\ldots$ & $\ldots$ & $\ldots$ & $\ldots$ & \\
\hline Mostly dissatisfied & $\ldots$ & $\ldots$ & $\ldots$ & $\ldots$ & \\
\hline Somewhat dissatisfied & $\ldots$. & $\ldots$ & $\ldots$ & $\ldots$. & \\
\hline Neither satisfied nor dissatisfied & 2 & $1.3 \%$ & $\ldots$ & $\ldots$ & \\
\hline \multicolumn{5}{|l|}{ Somewhat satisfied } & \\
\hline Mostly satisfied & 22 & $14.7 \%$ & 18 & $12.0 \%$ & \\
\hline Completely satisfied & 126 & $84.0 \%$ & 132 & $88.0 \%$ & \\
\hline \multicolumn{5}{|c|}{$\begin{array}{l}\text { 2- Environmental conditions in the recovery room (number of beds, personal bedside } \\
\text { cabinet, location of bathroom, privacy) }\end{array}$} & \multirow{8}{*}{.118} \\
\hline Completely dissatisfied & 0 & $.0 \%$ & 2 & $1.3 \%$ & \\
\hline Mostly dissatisfied & 2 & $1.3 \%$ & $\ldots$ & $\ldots$. & \\
\hline Somewhat dissatisfied & $\ldots$ & $\ldots$ & $\ldots$ & $\ldots$ & \\
\hline Neither satisfied nor dissatisfied & 2 & $1.3 \%$ & $\ldots$ & $\ldots$. & \\
\hline \multicolumn{5}{|l|}{ Somewhat dissatisfied } & \\
\hline Mostly satisfied & 27 & $18.0 \%$ & 20 & $13.3 \%$ & \\
\hline Completely satisfied & 119 & $79.3 \%$ & 128 & $85.3 \%$ & \\
\hline \multicolumn{5}{|l|}{ 3-Waiting time } & \multirow{8}{*}{$.000 *$} \\
\hline Completely dissatisfied & $\ldots$ & $\ldots$ & 6 & $4.0 \%$ & \\
\hline Mostly dissatisfied & $\ldots$ & $\ldots$ & 21 & $14.0 \%$ & \\
\hline Somewhat dissatisfied & 27 & $18.0 \%$ & 26 & $17.3 \%$ & \\
\hline Neither satisfied nor dissatisfied & 3 & $2.0 \%$ & 0 & $.0 \%$ & \\
\hline Somewhat satisfied & 24 & $16.0 \%$ & 31 & $20.7 \%$ & \\
\hline Mostly satisfied & 50 & $33.3 \%$ & 7 & $4.7 \%$ & \\
\hline Completely satisfied & 46 & $30.7 \%$ & 59 & $39.3 \%$ & \\
\hline
\end{tabular}

Table (1): Shows that there is significant difference between women in assisted reproduction center in women health hospital and in Banon center as regards residence and level of education with p.v $(.009, .002)$ respectively .

Table (2): Shows that there is statistical significant difference between satisfaction in public IVF center and satisfaction in private center as regards information provided about IVF procedure with p.v $(.000$,$) .$

Table (3): Shows that there is statistical significant difference between satisfaction in public IVF center and satisfaction in private center as regards staff willingness to listen carefully and help patients , Regular progress update on condition is in place with p.v (.005, .003) respectively.

Table (4): Shows that there is no statistical significant difference between satisfaction in public IVF center and satisfaction in private center as regards environmental conditions \& there is statistical significant difference between satisfaction in public
IVF center and satisfaction in private center as regards waiting times with p.v (.000)

\section{Discussion}

Patient satisfaction is an important and commonly used indicator for measuring the quality in health care. Patient satisfaction affects clinical outcomes, patient retention, and medical malpractice claims. (Prakash, 2010) So, this study will shed more light on women satisfaction with IVF services in two centers.

One of the most important findings to arise from this study was the high level of satisfaction with the medical care received by women undergoing IVF.

In the current study, regarding women's satisfaction in both centers, it was noticed that majority of infertile women are satisfied with the care they received both groups, these results agree with Gonen (2016) in his study conducted in 8 public IVF units in public hospitals in Israel to investigate women' satisfaction with various aspects of fertility care who reported that 
level of satisfaction was high among IVF patients with the medical care they received.

The current study was the first study that investigated comparison between women satisfaction in public IVF center and women satisfaction in private center satisfaction in woman's health hospital, Assuit university. There are no previous studies.

Regarding women's Satisfaction about information provided in public IVF center and in private center, there is statistical significant difference between satisfaction in public IVF center and satisfaction in private center in relation to information on the chances of success, information on (prognosis, different treatment options, clinical aspects, and possible side effects of treatment), information about potential health problems of "test tube babies" (defects, prematurity), information about medical issues during pregnancy (multiple pregnancies, ectopic pregnancies, miscarriages, etc.), information on treatment costs with p.v (.000, .000, .004, .026, $.000)$. This result is interpreted by public IVF units are very busy and pressured. Consequently, personal attention and the detailed information relevant to a specific individual cannot always be given as desired.

Regarding women's satisfaction about staff communications \& counseling and support among both groups, there is statistical significant difference between satisfaction in public IVF center and satisfaction in private center as regards staff willingness to listen carefully and help patients, Regular progress update on condition is in place with p.v (.005, .003) respectively.

Also, this could be interpreted by that the public IVF units are very busy and pressured. Consequently, there is no time to listen carefully and help patients, also to provide the woman information about progress of the condition and there was lack in communication between staff and women.

Regarding women's satisfaction about physical conditions \&waiting time among both groups, there is no statistical significant difference between satisfaction in public IVF center and satisfaction in private center as regards environmental conditions \& there is statistical significant difference between satisfaction in public IVF center and satisfaction in private center as regards waiting times with p.v (.000).

\section{Study strengths \& limitations}

Merits

- The prospective way of the study \& two centers included.

- This is a new idea and it has not been applied in Egypt before.

\section{Limitations}

- There were no previous studies.

\section{Conclusion}

The majority of infertile women were satisfied with the care they received but there was statistical significant difference between satisfaction in public IVF center and satisfaction in private center as regards information provided, staff willingness to listen carefully and help patients.

\section{Recommendations}

1- Other studies should also be conducted in other centers to further investigate the issue and reconfirm the reliability and validity of the assessment instrument in evaluating patient' satisfaction, in order for it to be applied at IVF centers.

2- Medical \& nursing staff should spend more time in consulting and explaining to women to improve women's satisfaction.

3- Develop nursing training programs about how to evaluate women's satisfaction about IVF care.

\section{References}

1. Eltoukhi N., Azzam H., Hani M., AbdelMonem A., (2017): Relationship between women's body mass index and success rate of in vitro fertilization. Malaysian Journal of Medical research, 1(2), 8-17.

2. Bayer, S., Alper, M., \& Penzias, A., (2017): The Boston IVF handbook of infertility: a practical guide for practitioners who care for infertile couples: CRC Press.

3. Gonen, L., (2016): Satisfaction with in vitro fertilization treatment: patients' experiences and professionals' perceptions. Fertility research and practice, 2, 6 .

4. Ghraib, S., \& Khait, A., (2017): The Relationship between Primary Infertility and Depression among Women Attending Royal Medical Services Hospitals in Jordan. $J$ Community Med Health Educ, 7, 21610711.1000533.

5. Kamphuis, E., Bhattacharya, S., Van Der Veen, F., Mol, B., \& Templeton, A., (2014): Are we overusing IVF? Bmj, 348, g252.

6. Obioha, J., Ikechebelu, J., Eleje, G., \& JoeIkechebelu, N., (2014): Knowledge and attitude of nurses towards in-vitro fertilization: A prospective cohort study. Obstet Gynecol Cases Rev, 1, 006. 
7. Prakash, B., (2010): Patient satisfaction. Journal of Cutaneous and Aesthetic Surgery, 3, 151.

8. Zegers-Hochschild, F., Adamson, G., Dyer, S., Racowsky, C., de Mouzon, J., Sokol, R., Rienzi, L., Sunde, A., Schmidt, L., \& Cooke, I., (2017): The international glossary on infertility and fertility care, 2017. Oxford University Press. 